\title{
Louis-Antoine, marquis de Caraccioli, Le Livre à la mode suivi de Le Livre des quatre couleurs
}

\section{Valentina Ponzetto}

\section{(2) OpenEdition}

1 Journals

\section{Edizione digitale}

URL: https://journals.openedition.org/studifrancesi/26386

DOI: 10.4000/studifrancesi.26386

ISSN: 2421-5856

\section{Editore}

Rosenberg \& Sellier

\section{Edizione cartacea}

Data di pubblicazione: 1 avril 2007

Paginazione: 184

ISSN: 0039-2944

\section{Notizia bibliografica digitale}

Valentina Ponzetto, «Louis-Antoine, marquis de Caraccioli, Le Livre à la mode suivi de Le Livre des quatre couleurs», Studi Francesi [Online], 151 (LI | I) | 2007, online dal 30 novembre 2015, consultato il 23 novembre 2021. URL: http://journals.openedition.org/studifrancesi/26386 ; DOI: https://doi.org/ 10.4000/studifrancesi.26386

Questo documento è stato generato automaticamente il 23 novembre 2021.

\section{(c)}

Studi Francesi è distribuita con Licenza Creative Commons Attribuzione - Non commerciale - Non opere derivate 4.0 Internazionale. 


\title{
Louis-Antoine, marquis de Caraccioli, Le Livre à la mode suivi de Le Livre des quatre couleurs
}

\author{
Valentina Ponzetto
}

\section{NOTIZIA}

LOUIS-ANTOINE, marquis DE CARACCIOLI, Le Livre à la mode suivi de Le Livre des quatre couleurs, textes présentés et annotés par Annie RICHARDOT, Saint-Étienne, Publications de l'Université de Saint-Étienne, 2005, pp. 105.

1 È stato detto che il Settecento è un'oasi colorata fra il nero dell'età della Riforma e della Controriforma e quello dell'Ottocento borghese. Gli abiti le pietanze, i mobili, gli appartamenti stessi, tutto si fa variopinto, si vuole grazioso. Perché non anche i libri? È questa la curiosa idea del marchese Caraccioli, un poligrafo autore di apologetica cristiana e satire di costume, inviso ai philosophes e fors'anche per questo oggi caduto nell'oblio. «Un siècle aussi joli que le nôtre, doit-il écrire en caractères noirs?» si interroga il marchese nella préface. «Ne convient-il pas que l'impression d'un livre réponde au livre même, et que des lettres toutes jolies expriment de jolies pensées?». Ecco allora i due volumi del Livre à la mode, il primo verde e il secondo rosa, e il Livre des quatre couleurs, rosa e blu, che ostentano la loro joliesse come gioco, ma anche come provocazione. Una piccola curiosità degna dell'attenzione dei bibliofili che Annie Richardot, già apprezzata autrice di Le Rire des Lumières e Les caprices de Cythère, ci ripropone qui in tutta la sua brillante quadricromia.

2 Il variare dei colori è presentato dall'autore come un modo per accattivarsi il pubblico, un omaggio al culto della piacevolezza, della frivolezza e dell'effimero imperanti nella buona società del 1760. Con leggera ironia quasi ogni pagina del libro denuncia infatti la passione sfrenata e sconsiderata per la moda, il «moderno», il nuovo ad ogni costo, addita la superficialità e l'incostanza della bonne compagnie. 
3 L'atteggiamento dell'autore, come sottolinea la curatrice, è ambiguo. L'opera è certo una satira di costume, una critica degli atteggiamenti alla moda e in particolare dei petits-maîtres e delle petites maîtresses, che tanto inchiostro hanno fatto scorrere al tempo e che qui sono messi in scena con tutte le loro ridicole manie. Ma al tempo stesso l'ironia è bonaria e tende a scomparire in un mimetismo perfetto del tono e dell'enjouement dei soggetti esaminati. Il risultato è per altro di assai piacevole lettura. Vale la pena, per esempio, di apprendere tutto sulle «différentes manières de se servir de l'éventail», cui è dedicato un intero capitolo, o di scorrere la vita, i viaggi e il testamento del cavalier Muscoloris, Grand petit-maître de l'Ordre de la Frivolité. 